\title{
Construction Risks Management of Building Projects in Sultanate of Oman: Contractor and Owner Perspective
}

\author{
Omar Aljassasi ${ }^{1}$ and Mahmoud Dawood ${ }^{1 \#}$ \\ ${ }^{1}$ Department of Civil Engineering, Middle East College, Muscat, OMAN \\ \#Advisor
}

ABSTRACT

Managing risks is vital for any construction project to avoid cost overrun, schedule delay, and to meet the quality requirements. Over the last 10 years, the building market has evolved rapidly; businesses face greater risk and complexity than ever before. Risk assessment has been an integral aspect of the project management process. Because of the time and costs overruns involved with building projects, risk of building has become the focus of concern. This research focuses on exploring risk control techniques in construction industry. Risk reduction and management of planning is a critical approach that helps one to deal with the removal of different risks, their analyses, and the remedial steps that can be taken to remove them in a given project. Any construction company has to set up a risk management scheme to improve performance, reduce costs and increase sales. In this regard, set of principles have to be adopted for the development of ethical risk management planning decisions. In addition, hazards ought to be taken care of such that ensures a suitable norm of security for human wellbeing and the earth and at any rate offers the level of wellbeing that is sensible to people in the future today; there doesn't seem, by all accounts, to be any lawful avocation for limiting likely wellbeing and condition chances.

\section{Introduction}

Risk control in construction industry is a critical tool for maintaining the project's priorities in terms of time, cost, security, performance and environmental atmosphere. Development ventures are conducted in areas with varied intertwined activities and thus there is still risk and uncertainty (Jaafari, 2001; Rozenes, 2013). Construction performance is one of the most important productivity trends of any construction project. The success of these undertakings is fundamentally dependent on effective management to plan, track and execute project activities and take the appropriate steps to promote the execution of the individual tasks. The risk evaluation is maybe the most troublesome part of task the board. A venture chief must have the option to consider and recognize the underlying drivers of the dangers, and screen those impacts through the undertaking to their effect. Besides, hazard appraisal on account of building venture the board is a far reaching and orderly strategy for distinguishing, assessing and responding to the dangers for accomplishing the undertaking objective (Keshk et al., 2018).

It is critical to utilize risk management (RM) from the beginning phases of a venture, from which expansive choices, for example, decision of arrangement and choice of plan frameworks can be influenced. The advantages of danger the board methodology incorporate danger recognizable proof and investigation, and improvement of venture the executive's measures in development, just as successful usage of assets. The structure business is heterogeneous, and amazingly mind boggling. There are a few expansive orders of structures that vary significantly from each other: business, non-private, strong, parkway, utility and modern structures. The arranging ventures incorporate new private 
and non-private development, rebuilding and redesign, just as open works estimates, for example, parks, streets, roadways, utility stations, scaffolds, passages and bridges (Iqbal et al., 2015). By pursuing the owners' viewpoint, we would concentrate our attention not on the general roles of various professionals such as administrators, engineers, construction designers, builders, suppliers, service providers, financial analysts and others but on the whole project management process for constructed facilities. To be sure, and specialty has made considerable strides in developing novel approaches and techniques to successfully execute projects. However, it is by understanding the whole project management process that these specialists can more easily cater with their skills to the owner's needs, market their specialties and improve the quality and effectiveness of their jobs. Improving project management not only helps the construction industry but can also act as a driver for both the national and global economies. However, in order to make significant improvements, we must first understand the construction industry, its business climate and the systemic constraints influencing its activities, as well as the nature of project management. The research would benefit from solutions to conditions that impact the risks of handling development in construction projects in Al-Duqum. The research would provide information on the threats and the consequences of the risks on the project and its management strategies. It will compensate for Al-Duqum area with sustainable environmental development programmes. It will offer a new approach for handling construction risks in industrial projects in Al-Duqum region to a contractors and owners.

\section{Risk and Uncertainty}

Danger may be defined as an unforeseeable event or circumstance that, when it occurs, has a positive or negative effect on a project schedule. A danger has a source, and if it happens, one result. Jaafari (2001) defined risk as the exposure to loss / gain, or the probability of loss / gain multiplied by its respective magnitude. It is said that accidents are probable if their probability is $100 \%$ or totally, zero if the chance of occurrence is $0 \%$. The Institute for Project Management adopted a Clear definition of risk as a single incident, which can have a positive or negative effect on the project. Risk has been defined as the probability of occurrence of some uncertain, unpredictable and even undesirable incidents that would impact the profitability potential of a given investment (Kartam \& Kartam, 2001), to illustrate the key objectives of the risk management activities survey. Risks and risks are a part of all industries, activities and trade. They influence all of the fundamental variables that decide planning, execution, control, change, behavior, clarify choices and make decisions. Any definition of risk is likely to hold a subjectivity factor, based on the essence of the risk and what is added to it. In certain cases, the vulnerability does not generally apply to the probability of negative outcomes. Good outcomes will emerge, and it is important that a definition of any reference to this point require risk.

It has suggested a variety of changes in the risk assessment process. Boehm recommended a two-phase process: risk evaluation that involves defining, assessing and prioritizing, and risk mitigation that involves risk management preparation, risk reduction, and risk analysis preparing, recording, and corrective action. Chapman ( 2003) described the approach to risk management as a multi-phase 'risk analysis' including risk recognition, estimation, control and management. Risk management forms one of the so-called nine aspects of project management (the other eight are coordination, communications, human resources, time, expense, reach, efficiency and procurement management), according to the Project Management Body of Expertise (PMI, 2001). The conventional view is that these roles should form the planning basis and that each of them should be the object of interest in each project process. A method for handling risk must be reasonable, realistic and cost-effective. Obviously the extent of which you evaluate danger depends on the situation. Just you can judge the value a formal risk analysis needs to put on it. Conventional education does nothing to encourage understanding of how unforeseeable life can be.

\section{Theoretical Framework}


Environmental issues influence construction projects significantly. The environmental impact on the project may include: decreased visibility and failure to navigate construction and operating instrumentation, disruptions in obtaining and/or distributing products (e.g., structural supplies, reagents) and/or shipping goods, improvements in employee's ability to reach the location (e.g., if a road is to be scrubbed out), damage to facilities, improved capability. Financial problems have a significant impact on building programs. Possible strategies to reduce financial-related delays such as business structuring, not over-development, coaching on cash flow control, proper use of risk management, being receptive to contract approval, agreeing on a respectable remunerator, and using payment bonds with banks and customers have been urged on purchasers and contractors, severally.

Theoretical risk analysis methods for the building industry have been developed over several years, but only rarely implemented in real life except for the few places and few sectors of private sector multidisciplinary clients (Dilger, 2000). For local or multinational projects, the risk factors for all the projects can be identical. Risk factors include reduced specification planning, poor quality control and unsafe products resulting in unsafe jobs. Deficient planning, bad weather, late building site ownership, fluctuation in labor and availability of supplies, unexpected ground conditions and incompetent relations and communication with the parties concerned are reasons for schedule delays. Both these risk factors may be managed by careful project management, but the risks can differ with each project due to the particular nature of the projects due to which it is impossible to determine these risks beforehand (Dziadosz \& Rejment, 2015)

\section{Factors Affecting Construction Management Risks}

Any building scheme carries some degree of risk. Identifying and mitigating risks requires experience, careful planning and the capacity to make sound decisions with ease (Dilger, 2000). When challenges become a possibility they can be counterproductive to the successful execution of the project. Proper management of risks can lead to higher revenues, improved customer relationships and the opportunity for market growth and progress (Jones, 2020)

\section{Labor shortages and growth problems}

When chipping away at new errands, not getting enough staff around to complete work or arrive at creation targets is a significant concern. The undertaking could experience the ill effects of longer development courses of events and potential deferrals in conveying the task on an ideal opportunity to the buyer, without the labor to direct the activity. Development industry has been bothered with work lack issues since recuperation from the last downturn started. A large number of the expert representatives who either resigned or sought after new openings after the downturn were given up or leaving the business. Development firms have battled to top opportunities to keep off with the rising requirement for their administrations. Indeed, even as the structure business has utilized 170,000 of every 2018 up until this point, the quantity of work openings has become progressively in the course of recent months. As per the Bureau of Labor Statistics' new investigation on Work Opportunities and Workforce Turnover Review (JOLTS), there were 263,000 opening under development in June (Jones, 2020).

Health is also a risk factor which needs to be discussed when working with new staff. They lack the experience and skills to be able to obey any of the rules or understand dangerous working site environments. Protection readiness is just as critical, if not more, than skill training and should be a top priority for new recruits. Offer equal wages and incentives to fix labor force shortages, and create a stable workplace community that values employees and encourages hard work and loyalty. That takes time and resources to invest in training and development at your workforce (Jones, 2020). 


\section{Dangers to health and welfare}

The highest priority should be to ensure staff health on the work site. Conditions on the field can change quickly, and there could be unexpected threats whenever possible. Major accidents can result in serious illness or death to the staff. Your goal should be to be accident-free on every job and to ensure that every worker goes home safely to his families. Keep a meeting with the staff and subcontractors on the safety kick-off before starting work. Cover the risks and hazards present at the building process. Make sure everybody has read and understood the safety plan you have developed for the project (Jones, 2020).

\section{Primary Subcontractor}

For general contractors a major risk factor is dealing with a subcontractor that struggles to perform on a project. A defaulting subcontractor who doesn't uphold its contractual obligations would totally wreck your project timeline and destroy your profit margin. Any subcontractors could also be hit by project delays which may result in costly rework. No subcontractor will begin a job with the intention of defaulting on the work. Before they begin to get paid, subcontractors have to pay a large portion of the costs on a project. This could potentially lead to cash flow problems if they over-extend by doing too much work or spending for other projects (Jones, 2020).

\section{Adjusting Orders}

Change orders are an intrinsic part of architecture, and can be a major risk factor if not done properly. A change order is simply an addendum or an addition to the original construction arrangement or duration of operation. This can be introduced by the proprietor, general contractor, or subcontractors. For reasons such as omissions or inconsistencies in the original scope of work or ambiguous design proposals, they typically require additional work undertakings. Increased project costs, delays in meeting contract deadlines, workflow interruptions and the failure to complete a project on schedule are some of the issues caused by poorly handled change orders. Managing change orders requires preparation, communication and good collaboration with all the partners involved in the project. Disagreements on what facilitates a change order are common, since they affect the different parties involved in various ways. Clarify some discrepancies with the essence of the job, plans and specifications, or goods ambiguous. Make sure the subcontractors are focused about the work they were hiring to do. This reduces the need to transfer commands down the line (Jones, 2020). Other important risk factors for building projects include inadequate sketches and improperly specified layout, construction flaws, uncertain site conditions, badly drafted contracts, excessive material cost changes, and poor project management. Proper detection and evaluation of building risks are crucial to successful and efficient project completion.

\section{Impact of risks on Construction Projects}

As risks come to fruition, they can negatively affect the budgets, schedules and performance of the initiative, leading to down-line delays and disputes. The good news is that many of these risks can be addressed and mitigated with proper planning and successful project management. Effective use of project management approaches such as risk and value management is considered to be essential support structures and to offer them productivity, cost, time and development control (Fewings \& Henjewele, 2019), they both establish an intertwined project success strategy. While project risk management is a complex process and should be in accordance with the size and complexity of the project considered. 
Good risk management within the construction sector requires a high degree of collaboration and communication with all stakeholders. Having people on the same page and working together will help you understand and mitigate threats before they became a problem. Note that tasks will offer great rewards when treated correctly. Generally, risk assessment was an important part of the project management process. Because of the time and costs involved in construction projects, building risk became the focus of interest.

\section{Research Methods}

To confirm old knowledge and create new information, study is rigorous, systematic inquiry or review. There are two types of research approaches, the quantitative and qualitative analysis (Naoum, 2012). Objective techniques aim at collecting quantitative data and examining the relationships between facts and how certain facts and experiences are compatible with the findings and results of a previously conducted research (Fellows \& Liu, 2015), while qualitative approaches seek to obtain perspective and understand people's perceptions of the "world" as persons or cultures. Qualitative analysis is in effect "subjective," focusing ideas, expectations etc. In this research, a quantitative approach is chosen to analyse the variables and factors that affect risk management practices in construction projects in the AlDuqm Area and to decide if there are structured risk management techniques across the contracting firms.

The research design refers to the holistic approach you use to incorporate the various components of the study in a coherent and logical manner, thus ensuring that you are successfully addressing the research issue; it is the blueprint for data collection, assessment and review. The task of the design of a study is to ensure that the collected knowledge allows you to solve the analysis problem as easily as possible. In social science analysis, usually deciding the kind of evidence needed to test a hypothesis, evaluate a process or properly describe a phenomenon involves collecting details relevant to the study question. However, researchers will also start their experiments excessively early, before reflecting seriously about what data is needed to answer the report's study questions. Without addressing these definition problems beforehand, the findings obtained are ambiguous and unconvincing and thus the ultimate research question will not be answered properly (Karlsson et al., 2011). In this research work, descriptive research design is used for analyzing the basic facts and figures in the questionnaire survey. Descriptive analysis designs tend to offer answers to the questions of who, what, where, where, and how they contribute to a specific research problem; a descriptive project cannot conclusively decide why. Descriptive analysis is used to collect knowledge about the present state of the phenomenon and to explain, "What does happen" in reference to factors or circumstances in a situation (McNabb, 2015). The descriptive analysis is done for management of risk in the construction of Al-Duqm area in the contractors and owner's perspectives.

\section{Results Analysis and Discussion}

Data processing for filing questions was focused on online websites due to COVID-19. The personal interview, which is a face-to-face operation, was performed on Skype in which the respondents were asked questions with a brief explanation for the questionnaire's ideas and contents. The primary data is collected by questionnaire survey done online and secondary data is collected by already existing journals, books, websites and other valid articles. Validity refers to how often a computer checks what it is supposed to be. The fact that the measurement instrument lacks design defects is highly important. If an instrument is valid, it is in reality the concept it should be measuring. Validity has multiple dimensions and various approaches to judgment. The questionnaire was reviewed by two panels of experts. The first is asked to determine if the questions matched with the existence of the products and to what degree these products reflected the study problem description. The second is asked to assess if the tool used is objectively accurate and to make similarities and contrasts between questions in the model. Reliability of an instrument is the degree of precision with which it measures the property that it is supposed to measure. The less variation an instrument produces 
in repeated measurements of an element, the greater is its performance. Efficiency may be equated with the time, accuracy or efficiency of a measuring instrument.

Analysis is an interactive method which analyses the answers to see if these responses support the theory underlying each question (Enshassi et al., 2012). Usage of the Mathematical/Statistical Program for Social Sciences (SPSS) to quantitatively evaluate the data for questionnaire was used. Data review is conducted to rate the seriousness of the factors for the loss of the contractor in Al-Duqm Area. Comparison of mean values within classes and for the total sub-factors was accompanied by rating.

In the table 1, there is a list of risk factors which are causing issues in the management of risk construction in Al-Duqm area in Oman. Those factors were given in the questionnaire for analyzing the facts that the respondents have given to it. Mostly respondents are agreeing with the statement that the provided risk factors are correct and cause problem in construction management of Al-Duqm Area.

Table 1: Frequency distribution of risk factors

\begin{tabular}{|c|c|c|c|c|c|}
\hline Factors & $\begin{array}{l}\text { Strongly } \\
\text { Agree }\end{array}$ & Agree & Neutral & Disagree & $\begin{array}{l}\text { Strongly } \\
\text { Disagree }\end{array}$ \\
\hline $\begin{array}{l}\text { Delayed completion of the work in the period required } \\
\text { to understand from the contractors the nature of the } \\
\text { work }\end{array}$ & $7.9 \%$ & $63.2 \%$ & $10.5 \%$ & $15.8 \%$ & $2.6 \%$ \\
\hline $\begin{array}{l}\text { Faulty product stocks Not available (Cement and iron } \\
\ldots .\end{array}$ & 7.9 & 47.4 & 28.9 & 15.8 & - \\
\hline Design on a rush by the consultant not to study the soil. & 18.4 & 57.9 & 105 & 13.2 & - \\
\hline $\begin{array}{l}\text { Lack of consistency between quantity statement, draw- } \\
\text { ings and specifications }\end{array}$ & 5.3 & 57.9 & 31.6 & 5.3 & - \\
\hline $\begin{array}{l}\text { Faulty (incorrect) style the contractors' analysis of the } \\
\text { project caused a delay }\end{array}$ & 13.2 & 39.5 & 26.3 & 21.1 & - \\
\hline Unfavorable conditions the climate & 2.6 & 47.4 & 21.1 & 21.1 & 7.9 \\
\hline $\begin{array}{l}\text { Varied efficiency of labor and of resources of SME en- } \\
\text { trepreneurs "Riyada" }\end{array}$ & 13.2 & 39.5 & 39.5 & 7.8 & - \\
\hline $\begin{array}{l}\text { Poor communication between the offices at home and } \\
\text { in the field (contractor side }\end{array}$ & 26.3 & 34.2 & 23.7 & 10.5 & 5.3 \\
\hline $\begin{array}{l}\text { Bad contact between the parties concerned Between the } \\
\text { contractor, the consultant and the Authority }\end{array}$ & 28.9 & 50.0 & 15.8 & 2.6 & 2.6 \\
\hline $\begin{array}{l}\text { Management changes from the contractor without the } \\
\text { knowledge of the consultant and the Authority }\end{array}$ & 34.2 & 28.9 & 21.1 & 13.2 & 2.6 \\
\hline $\begin{array}{l}\text { Unavailability of resources from the contractor on time } \\
\text { without the knowledge of the consultant and the } \mathrm{Au}- \\
\text { thority }\end{array}$ & 13.2 & 50.0 & 26.3 & 7.9 & 2.6 \\
\hline $\begin{array}{l}\text { Ambiguous planning given the complexity of the pro- } \\
\text { ject from contractor and the subcontractor without the } \\
\text { knowledge of the consultant }\end{array}$ & 26.3 & 52.6 & 13.2 & 5.3 & 2.6 \\
\hline All Parties face operational loss & 15.8 & 28.9 & 36.8 & 10.5 & 7.9 \\
\hline
\end{tabular}

In the table 2, there are statements regarding counteractive method, which can be used in place of risk management for a short period of time. Respondents mostly agree with the given statements in the table. Few respondents also oppose to the statements. 
Table 2: Frequency distribution of Counteractive Methods

\begin{tabular}{|l|l|l|l|l|l|}
\hline Methods & Never & Rarely & Sometimes & Often & Always \\
\hline $\begin{array}{l}\text { Using the methods of computational risk re- } \\
\text { duction for precise time estimation. }\end{array}$ & $15.8 \%$ & $18.4 \%$ & $47.7 \%$ & $7.9 \%$ & $10.5 \%$ \\
\hline $\begin{array}{l}\text { To create a good plan, it relies on moral } \\
\text { judgment. }\end{array}$ & $2.6 \%$ & $26.3 \%$ & $21.1 \%$ & $26.3 \%$ & $23.7 \%$ \\
\hline $\begin{array}{l}\text { Produce a correct timetable when reviewing } \\
\text { details regarding a project }\end{array}$ & $5.3 \%$ & $28.9 \%$ & $13.2 \%$ & $31.6 \%$ & $21.1 \%$ \\
\hline Planning replacements as stand-by & $13.2 \%$ & $13.2 \%$ & $23.7 \%$ & $42.1 \%$ & $7.9 \%$ \\
\hline
\end{tabular}

In the table 3, there are three risk analysis techniques given in questionnaire survey to which respondents agree that the statements are correct and can be used for risk management in Al-Duqm Construction Area.

Table 3: Frequency Distribution of Risk Analysis Techniques

\begin{tabular}{|l|l|l|l|l|l|}
\hline Methods & Never & Rarely & Sometimes & Often & Always \\
\hline $\begin{array}{l}\text { Expert tools (including program products, } \\
\text { judgment support programs, code driven } \\
\text { analysis approaches like @Risk }\end{array}$ & $5.3 \%$ & $39.5 \%$ & $23.7 \%$ & $13.2 \%$ & $18.4 \%$ \\
\hline $\begin{array}{l}\text { Study of chance (study of the empirical } \\
\text { data) }\end{array}$ & $7.9 \%$ & $36.8 \%$ & $26.3 \%$ & $23.7 \%$ & $5.3 \%$ \\
\hline Analyzing sensitivity & $5.3 \%$ & $36.8 \%$ & $34.2 \%$ & $15.8 \%$ & $7.9 \%$ \\
\hline
\end{tabular}

\section{Conclusions}

This research is undertaken to define risk factors, their significance and their distribution for the building industry. Additionally, risk assessment actions, risk analysis methods and their feasibility and application are agreed on. The above themes are explored from the viewpoints of contractors and owners. These priorities have been taken forward, some trends have been inferred and some steps have been proposed that may strengthen procedures in risk management. Usually the building contractor struggles to operate on time or price overruns are affected because of inadequate, un-systematized risk management. The causes of failure (risk factors) are often inherent to the project or embedded in the outer environment, some of which may also be governable, and other factors may be uncontrollable as well. All manner of risks need various strategies of mitigation. It cannot delete the uncontrollable ones and can only generate adequate responses to dilute their impact. In the bud the controllable ones can be nipped and can be stopped at delivery. The inner ones have their roots in the corporation and want efficient use of the internal capital to deter them, while the outer ones want constant scanning and declaration of the surroundings.

Most projects do not follow expectations or the production and expense goals. As a result, risk control becomes an essential aspect of handling the building. Risk management intends to identify and manage the potential and unforeseen issues that may arise during implementation of the project. It also aims to classify as many risk incidents as possible to mitigate their effects on the project, coordinate reactions to incidents that are expected to occur, and provide contingency funding to cover risk events that do occur. Risk management and risk funding are the most critical concerns that the project owner involved has in risk policy. Risk management is defined as which group is responsible for disclosing and passing the threats and risks. Risk support can be defined as the way risk allocation or contingency 
budget will be used and used. Participants make decisions to determine the structure and procedures of a project which influence the parties' obligations. The construction industry has attributes that distinctly differentiate it from other economic sectors. It is decentralized, extremely vulnerable to economic conditions and highly competitive due to the vast number of businesses and relative ease of entry. It is essentially considered a dangerous company because of these particular characteristics.

In this study, the detection of risk factors posed by the construction industry focuses on developing information about building risks, their impacts and mitigating actions that can be taken to prevent or reduce the risk effects. Techniques have also been researched for evaluating the risks. The primary aim of this analysis, however, was to determine the extent and distribution of certain risk factors. The goal of this research is to analyze the key risk factors and to identify some factors that may be faced in the construction region of Al-Duqm in Oman. Analysis of these risk factors has been conducted in order to measure their effect on building projects and to assign the risk factor to the community in the best position to deal with those conditions. In many ways the building company would increase the productivity of its workers. The contractor here dismissed the entire workforce of the project to enhance the work of the workers. The results were useful for the company's benefit; i.e. in the past, the contractor's staff consisted of two structural engineers, and they could not manage the workload. The technical team currently consists of one project manager, two structural engineers, one part-time mechanical engineer and two Al-Duqm superintendents.

In addition, some threats have a greater effect on the project and area unit, which is important for its timely completion, while others do not require consideration because they are of marginal significance. The respondents did not use computational instruments, computer programs or sensitivity analyses; they still focused on subjective estimation and empirical analysis to evaluate the results of the risk. Contractors and owners continue to focus on traditional approaches to the management of risk factors and their consequences; the most widely used form of managing accident accidents was to use impartial judgment to handle risk factors. The research resulted in solutions to the factors influencing the likelihood of handling development in building projects in Al-Duqum. It gave details on the threats and the effect of the risks on the project and the monitoring techniques. It provided for Al-Duqum area with sustainable environmental development programmes. A new approach for handling construction risks in industrial projects in the Al-Duqum region is being recommended to contractors and owners

\section{References}

Chapman, C. (2003). Project risk management. John Wiley \& Sons, Inc.

Dilger, C. W. (2000). Project risk management for international petroleum exploration and development ventures. University of Calgary.

Dziadosz, A., \& Rejment, M. (2015). Risk Analysis in Construction Project - Chosen Methods. Procedia Engineering, 122, 258-265. https://doi.org/https://doi.org/10.1016/j.proeng.2015.10.034

Enshassi, A., Arain, F., \& Tayeh, B. (2012). Major causes of problems between contractors and subcontractors in the Gaza Strip. Journal of Financial Management of Property and Construction.

Fellows, R. F., \& Liu, A. M. M. (2015). Research methods for construction. John Wiley \& Sons.

Fewings, P., \& Henjewele, C. (2019). Construction project management: an integrated approach. Routledge.

Iqbal, S., Choudhry, R. M., Holschemacher, K., Ali, A., \& Tamošaitienè, J. (2015). Risk management in construction projects. Technological and Economic Development of Economy, 21(1), 65-78.

Jaafari, A. (2001). Management of risks, uncertainties and opportunities on projects: time for a fundamental shift. International Journal of Project Management, 19(2), 89-101.

Jones, K. (2020). Construction Risk Management: Identifying and Managing Project Risks. https://www.constructconnect.com/blog/identifying-managing-construction-project-risks

Karlsson, J., Marx, R. G., Nakamura, N., \& Bhandari, M. (2011). A practical guide to research: design, execution, and publication. Arthroscopy, 27(4), S1-S112. 
Kartam, N. A., \& Kartam, S. A. (2001). Risk and its management in the Kuwaiti construction industry: a contractors' perspective. International Journal of Project Management, 19(6), 325-335. https://doi.org/https://doi.org/10.1016/S0263-7863(00)00014-4

Keshk, A. M., Maarouf, I., \& Annany, Y. (2018). Special studies in management of construction project risks, risk concept, plan building, risk quantitative and qualitative analysis, risk response strategies. Alexandria Engineering Journal, 57(4), 3179-3187. https://doi.org/https://doi.org/10.1016/j.aej.2017.12.003

McNabb, D. E. (2015). Research methods for political science: Quantitative and qualitative methods. Routledge. Naoum, S. G. (2012). Dissertation research and writing for construction students. Routledge.

PMI. (2001). Project management body of knowledge (pmbok® guide). Project Management Institute.

Rozenes, S. (2013). The impact of project management methodologies on project performance. Perspectives and Techniques for Improving Information Technology Project Management, 8, 14-23.

https://doi.org/10.4018/978-1-4666-2800-7.ch002 